\title{
Plant competition and slug herbivory: effects on the yield and biomass allocation pattern of Poa annua $\mathrm{L}$.
}

\author{
Miguel A. Rodríguez ${ }^{1,2, *}$, Valerie K. Brown ${ }^{1, * *}$ \\ ${ }^{1}$ Imperial College at Silwood Park, Ascot, Berks SL5 7PY, UK. \\ ${ }^{2}$ Department of Ecology and Evolutionary Biology, University of California, Irvine, CA 92697, USA.
}

Received September 16 1996; revised June 23 1997; accepted July 211997

\begin{abstract}
A factorial greenhouse experiment was conducted to examine the overall impact of slug herbivory, plant density and neighbour identity on the yield and allocation pattern of the short-lived grass Poa annua. The effects of slug herbivory were compared in experimental plants at two densities in two types of culture: pure and mixed with Arabidopsis thaliana. All the plant parts of $P$. annua showed significantly greater biomass in mixed than in pure stands, and in low compared to high density stands. Slug herbivory consistently reduced the biomass of reproductive organs and the percentage of total biomass allocated to reproduction, whereas density had no effect on allocation. In mixed stands, the proportion of biomass allocated to reproductive organs and leaves was greater and lesser, respectively, than in pure stands. There were significant interactions between herbivory and culture for root biomass and for the percentage of biomass allocated to root and shoots, and between herbivory, culture and density for shoot, stem, leaf and total biomass. Slug herbivory reduced root biomass in pure stands, whereas it did the opposite in mixed stands. The root:shoot ratio did not vary between mixed and pure stands in the absence of slugs, while when slugs were present pure stands had lower root/shoot ratio than mixed stands. Except for reproductive structures, all the plant parts showed greater biomass in grazed than in ungrazed low density mixed stands, whereas the general trend in high and low density pure stands, and in high density mixed stands was that herbivory decreased biomass. The study indicates that the competitive ability of plants is conditioned by a variety of factors. Plant density, the identity of competitors, and occurrence of herbivory are all relevant factors, the particular combination of which will alter competitive interactions. (1) Elsevier, Paris
\end{abstract}

Plant-animal interactions / plant-plant interactions / invertebrate herbivory / life-history / density-dependent regulation

\section{INTRODUCTION}

The present investigation was designed to reveal the interactive effects of a common British invertebrate herbivore, the slug Deroceras reticulatum (Müller), plant density and neighbour identity on the yield and biomass allocation pattern of Poa annua L. (Gramineae). Specifically, we asked: Do slug herbivory, neighbour identity and plant density interact in their effects on either reproductive and vegetative biomass of $P$. annua? If so, what is the nature of this interaction? The effects of invertebrate herbivory and competition on the dynamics of plant assemblages have been widely studied over the past two decades, yet surprisingly, the interaction between these processes has been comparatively scarcely considered in experimental studies (e.g. [14, 17, 29, 30, 49, 55]). Whittaker [57] suggested that invertebrate herbivory effects are likely to be most conspicuous when grazed plants are competing with other plants for resources, since differential herbivory can provide a competitive advan- tage to the least damaged plants (e.g. $[6,17,29])$. Similarly, studies of the effects of vertebrate herbivory and artificial defoliation on the occurrence and nature of plants have shown that regrowth of defoliated plants may be different depending on competition from neighbouring plants (e.g. $[1,2,44]$ ). Recently, predictions on the outcome of interactions between (vertebrate and invertebrate) herbivory and plant competition for plant fitness have been put together under the frame of the compensatory continuum hypothesis [40]. Briefly, this predicts that, in favourable environmental conditions (i.e. with abundance of resources, low competition), the effects of herbivory on plant fitness are expected to be less detrimental than in more stressed situations (i.e. with resources in limited supply, intense competition). Results from the present research are interpreted in light of these hypotheses, as well as taking into account predictions derived from the $r$ - and $K$-selection concept [39, 48], which provides a theoretical linkage between popula-

\footnotetext{
* Present address: Area de Ecología, Facultad de Ciencias, Universidad de Alcalá, 28871 Alcalá de Henares, Spain. E-mail glmarfealcala.es.

**: Present address: International Institute of Entomology, (An Institute of CAB INTERNATIONAL), 56 Queen's Gate, London SW7 5JR, UK.
} 
tion density and allocation pattern. The $r / K$ concept predicts that populations having density-independent control are under positive selection to allocate more resources to reproduction ( $r$ strategy) than populations experiencing high density-dependent regulation ( $K$ strategy).This is based upon the notions that reproduction and growth are competing activities in a plant ([50] and references therein), and that growth tends to concentrate in plant parts whose function is most limited by the environment $[11,18]$.

$P$. annua is an iteroparous short-lived, tiller-forming grass that flowers when small and continues to grow, flower and set seed until killed by extrinsic causes, such as frost, drought, or herbivory [4, 38]. P. annua grown on putting greens can be kept alive indefinitely by weekly mowings, whereas in natural habitats, where it is allowed to flower, it is most commonly an annual [38]. According to Ellis et al. [22], this is a colonizing species which grows mainly in disturbed areas, such as cultivated gardens, roadsides and pastures, and has spread from its centre of origin in Europe throughout temperate regions of the world. A lot of research has been devoted to design strategies to control $P$. annua infestation in pastures (e.g. [33]), as well as to improve its quality in putting greens (e.g. $[10,16])$. In addition, $P$. annua has also been considered in some studies on plant-slug interactions $[8,19$, 20], and in a number of studies of life histories, since it possesses a wide range of life-history variation $[21$, $22,36,37,38,54]$.

Slugs are a serious pest for many crops and pastures, for which extensive research has been devoted to quantify their damages $[3,29]$, as well as to establish ways of minimising them. The latter include both evaluations of the molluscicidal properties of different chemicals [23, 34], and analyses of the potential for alternative food resources (particularly, weed species invading the crops) to reduce slug damage [15]. Compared with what happens with insects and mammals, the interaction of terrestrial molluses with their food plants has been scarcely considered in basic ecological studies $[8,17,19,20,29,30,31,47,49]$. Slugs have been used as examples of generalist feeders to test predictions based on theoretical models of plant-herbivore coevolution [13]. Yet, it is clear that slugs are not indiscriminate feeders, but actively select certain foods in preference to others $[13,15,19,30,47,53]$. Dirzo [19] defined slugs as being acceptability-moderated generalists; that is, species capable of taking a wide variety of food but showing a distinct order of preference. In our view, the characteristic of slugs of being selective in their diet, but not so specialized as to complete reliance on single food plants, makes them particularly appropriate for studying plant-animal interactions.

\section{MATERIALS AND METHODS}

The study, undertaken in a greenhouse, employs two species commonly ocurring in early successional habitats at Silwood Park, England. It focuses on P. annua, but employs Arabidopsis thaliana (Cruciferae) as a weaker interspecific competitor, known to be highly palatable to slugs ([13]; pers. obs.). Seeds of the two species were obtained from commercial suppliers and were germinated in separate plastic trays filled with compost. After 5 days, they were transplanted to $42 \times$ $24 \times 8 \mathrm{~cm}$ plastic trays filled to within $1 \mathrm{~cm}$ of the top with compost. Trays were watered as necessary. Slugs (D. reticulatum) were collected in the field at Silwood Park, and slugs of comparable size $(c .1 \mathrm{~cm}$ long) were used [17]. Slugs of the same size were selected to give consistent potential herbivory.

The experimental design was a full factorial having the culture (pure or mixed culture with A. thaliana), density ( 24 or 40 plants per tray, equalling 238 and 397 plants $\cdot \mathrm{m}^{-2}$ ), and herbivory (presence or absence of slugs) as factors. There were 40 trays arranged in five blocks, each containing a replicate of each possible treatment combination. In the mixed stands, the seedlings of the two species were arranged alternately so that the closest neighbours to each $P$. annua plant were always four $A$. thaliana plants. Microclimate variation is known to affect slug activity [25, 59]. Light intensity slightly varied across the greenhouse, for which the blocks were arranged so that potential light differences occurred between but not within blocks. Infestation levels in other lab experiments involving the same slug species go up to 155 slugs $\cdot \mathrm{m}^{-2}$ [17]. We aimed to achieve a constant, more moderate density of four slugs per grazed tray (40 slugs $\cdot \mathrm{m}^{-2}$ ), which can be considered a common infestation in field conditions [26]. For this, slugs were retained in the trays by plastic propagators hoods, which were applied to all treatments regardless of slug content. In addition, the grazed trays were inspected daily, and any dead slugs were replaced. Harvesting took place after 15 weeks, and involved plants not at the edge of the trays. Ten and eight plants were collected from high and low density pure stands, respectively, and 5 and 4 plants were collected from the high and low density mixed stands, respectively. The total number of $P$. annua plants collected was 270 . Unfortunately, the effects of slug grazing on A. thaliana were so extensive by the end of the experiment that foliar biomass meassurements, although planned, were not possible. In addition, the delicate nature of its fibrous root system made an assessment of belowground biomass impractical. P. annua plants were washed, divided into stem, leaf, inflorescence and root portions, dried in an oven at $60{ }^{\circ} \mathrm{C}$ for $48 \mathrm{~h}$ and weighed. 
Data analyses were undertaken using the average value per tray corresponding to each plant part. Model III four-factor analyses of variance were performed on log-transformed biomass parameters and on untransformed proportional parameters (angularly transformed proportional data rendered similar results), with the treatments being considered as fixed factors and block as a random factor [60].

\section{RESULTS}

\subsection{Treatment effects on Poa annua biomass}

Mean biomass values for each plant part are shown in table I. Biomass production by $P$. annua was significantly affected by culture and density for all the plant parts considered, whereas slug herbivory had only marginally significant main effects on the biomass of reproductive structures (table II). Biomass was greater in mixed compared to pure stands and in low compared to high densities (tables $3 \mathrm{a}$ and $\mathrm{b}$ ). Pure stands showed

a)

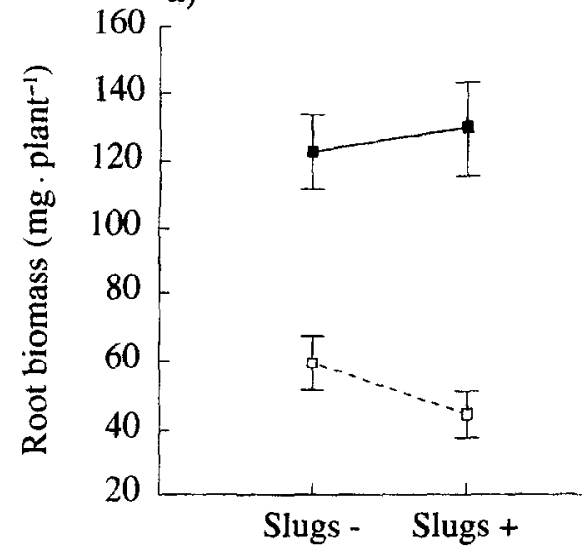

c)

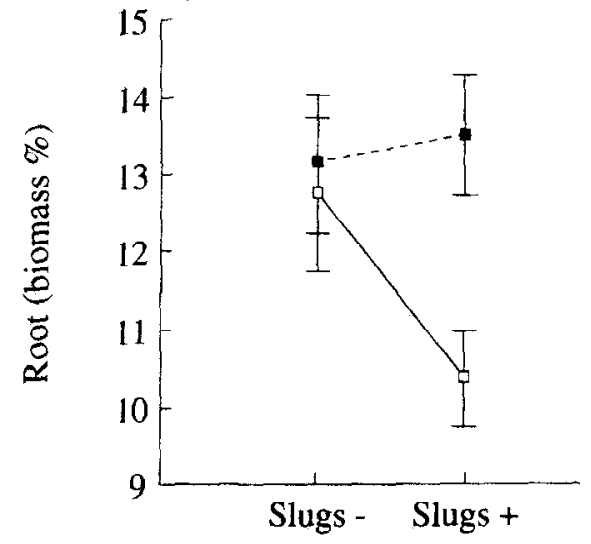

reduced total biomass, $53.3 \%$ compared with mixed stands, with the smallest reduction being in leaf biomass $(34.5 \%)$, and the highest in reproductive biomass (64.6 $\%$; table III a). Slug herbivory caused a reduction in reproductive biomass of $12.8 \%$ (table $I I I \mathrm{c}$ ). When grown in high density, $P$. annua reduced total biomass by $39.3 \%$ compared with low density (table III b). In contrast with culture and herbivory treatments, density had its lowest effect on reproductive biomass, which under high plant density was reduced by $29.1 \%$ compared with low density stands (table III b).

There were significant interactions between culture and slug herbivory for root biomass and in culture, density and herbivory for shoot, stem, leaf and total biomass (table II). In pure stands, plants grown with slugs had lower root biomass than those without slugs, while in mixed stands the opposite occurred (figure 1 a). In general, in pure culture and in high density in mixed culture, plants affected by slugs had lower biomass for all plant parts than those without
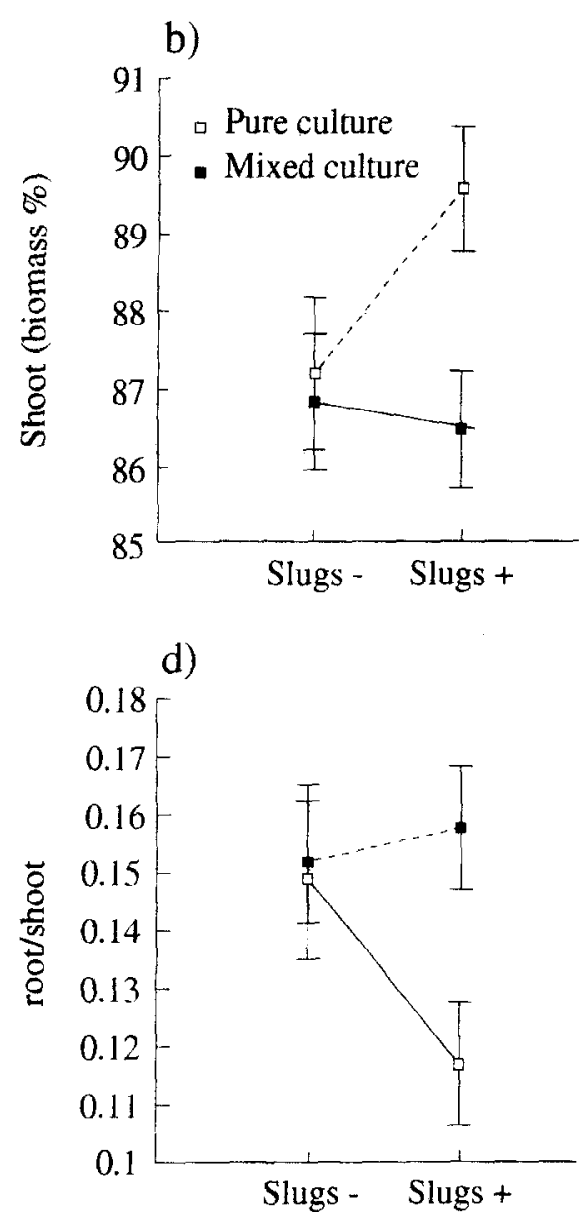

Figure 1. Interactions between culture and slug treatments (see fable II) for Poa annuo (a) root biomass, percentage of (b) shoot and (c) root biomass, and (d) root/shoot ratio. Narrow vertical bars show \pm 1 S.E.

Vol. 19 (1) 1998 
Table I. Mean values of Poa annua biomass ( $\mathrm{mg} \cdot$ plant $^{-1}$ ) at harvest (see text), when grown in pure or mixed cultures with Arabidopsis thaliana, at two densities and either the presence or absence of slug herbivory. Standard errors are in parentheses.

\begin{tabular}{lcccccccc}
\hline Culture & Density & Slug & total ${ }^{2}$ & shoot ${ }^{3}$ & stcm & leaf & repr. & root \\
\hline Pure & Low & - & $586(71)$ & $512(58)$ & $251(28)$ & $208(12)$ & $53(16)$ & $74(14)$ \\
Pure & Low & + & $549(60)$ & $490(56)$ & $245(33)$ & $190(12)$ & $55(15)$ & $59(9)$ \\
Pure & High & - & $342(18)$ & $297(18)$ & $137(13)$ & $130(11)$ & $30(5)$ & $45(6)$ \\
Pure & High & + & $293(23)$ & $263(19)$ & $127(15)$ & $110(13)$ & $26(6)$ & $30(4)$ \\
Mixed & Low & - & $1091(81)$ & $936(84)$ & $504(54)$ & $277(15)$ & $155(17)$ & $155(7)$ \\
Mixed & Low & + & $1238(67)$ & $1073(62)$ & $582(3)$ & $344(31)$ & $147(13)$ & $165(15)$ \\
Mixed & High & - & $781(35)$ & $690(34)$ & $355(22)$ & $210(6)$ & $125(15)$ & $91(6)$ \\
Mixed & High & + & $686(47)$ & $591(40)$ & $319(24)$ & $177(16)$ & $95(10)$ & $95(12)$
\end{tabular}

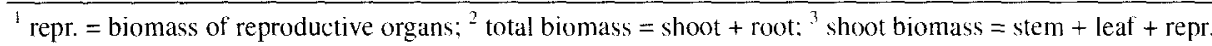

Table II. ANOVA results showing significant and non signilicant variance in (a) bionass production per plant, (b) percentage of biomass allocaled to different plant parts, and (c) various biomass ratios. Numbers in cells are $F$ values with d.f. $=1,4$ in all cases. ${ }^{\text {(k) }} P \leq 0.07 ; * P \leq 0.05$; *** $P \leq 0.01$; *** $P \leq 0.001$. Conventions as in table $l$.

(a) Biomass

\begin{tabular}{|c|c|c|c|c|c|c|}
\hline Treatment & lotal & shoot & stem & leat & repr. & root \\
\hline Culture & 84.3 *水冰 & $60.7 *$ & $52.2^{* * *}$ & $20.7 *$ & $65.0 * \%$ & $195.6 * * * *$ \\
\hline Density & $140.4^{1 *} ; *$ & $180.4^{* * * * *}$ & $270.5 \%$ & $392.5 * * *$ & $13.5^{4:}$ & $25.6^{* *}$ \\
\hline Slug & 0.4 & 0.2 & $<0.1$ & 0.3 & $6.0^{6}$ & 0.9 \\
\hline Culture Density & 0.8 & 0.7 & 2.2 & 4.0 & 0.5 & 2.8 \\
\hline Culture S Slug & 1.1 & 0.5 & 1.1 & 2.8 & 1.7 & $13.0^{* *}$ \\
\hline Density $\cdot$ Slug & 1.4 & 1.7 & 0.8 & 5.6 & 0.1 & 0.1 \\
\hline Culture - Density - Slug & $7.3^{(\%)}$ & $14.1 *$ & $8.2^{4}$ & $17.8 *$ & 0.5 & 0.1 \\
\hline
\end{tabular}

(b) Biomass (\%)

\begin{tabular}{|c|c|c|c|c|c|c|}
\hline Treatment & & shoot & stem & leaf & repr. & root \\
\hline Culture & & 1.8 & 2.0 & $17.9 *$ & $17.4^{*}$ & 1.8 \\
\hline Density & & 0.4 & 0.1 & 1.0 & 1.9 & 0.4 \\
\hline Slug & & 1.8 & 1.8 & 0.3 & $11.4 \%$ & 1.8 \\
\hline Culture $\cdot$ Density & & 0.3 & $<0.1$ & 0.9 & $<0.1$ & 0.3 \\
\hline Culture · Slug & & $11.2^{*}$ & $<0.1$ & 1.0 & 0.8 & $11.2^{*}$ \\
\hline Density $\cdot$ Slug & & 0.2 & 0.4 & $<0.1$ & $<0.1$ & 0.2 \\
\hline Culture $\cdot$ Density $\cdot$ Slug & & 3.9 & 3.5 & 2.0 & $<0.1$ & 3.9 \\
\hline \multicolumn{7}{|l|}{ (c) Biomass ratios } \\
\hline Treatment & root/shoot & repr./stem & repr./leat & repr./(stem + leaf $)$ & \multicolumn{2}{|c|}{ repr $/($ stem + leaf + root $)$} \\
\hline Culture & 1.6 & $13.1^{*}$ & $22.5^{* *}$ & $19.4 *$ & \multicolumn{2}{|c|}{17.8} \\
\hline Density & 0.4 & 1.9 & 0.9 & 1.3 & \multicolumn{2}{|c|}{1.6} \\
\hline Slug & 1.7 & $7.1^{1 * 1}$ & $7.3^{(*)}$ & $7.3^{(*)}$ & \multicolumn{2}{|c|}{$9.4^{*=}$} \\
\hline Culture $\cdot$ Density & 0.3 & $<0.1$ & 0.5 & 0.2 & \multicolumn{2}{|c|}{0.2} \\
\hline Culture $\cdot$ Slug & $9.9^{*}$ & 0.5 & 1.7 & 0.9 & \multicolumn{2}{|c|}{1.1} \\
\hline Density $\cdot$ Slug & 0.2 & $<0.1$ & 0.1 & $<0.1$ & \multicolumn{2}{|c|}{$<0.1$} \\
\hline Culture $\cdot$ Density $\cdot$ Slug & 4.2 & 0.1 & 0.1 & 0.1 & \multicolumn{2}{|c|}{$<0.1$} \\
\hline
\end{tabular}


Table III. Mean values for Poa annua biomass $\left(\mathrm{mg} \cdot\right.$ plant $\left.^{-1}\right)$ that were significantly affected by treatment (see table II). (a) Culture main effects; (b) density main effects; (c) slug herbivory main effect. Standard errors are in parentheses. Conventions as in table $I$.

\begin{tabular}{lcccccc}
\hline & total & shoot & stem & leaf & repr. & root \\
\hline (a) Culture & & & & & \\
Pure & $443(36)$ & $391(31)$ & $195(16)$ & $165(10)$ & $46(6)$ & $52(6)$ \\
Mixed & $949(57)$ & $823(50)$ & $440(29)$ & $252(17)$ & $130(8)$ & $127(10)$
\end{tabular}

(b) Density

Low $\quad 866(75) 753(64) 397(37) 256(16) 103(13) 114(12)$

High $\quad 526(50) 461(43) 239(24) 161(10) 73(10) 65(7)$

(c) Slug

\begin{tabular}{ll}
- & $94(12)$ \\
+ & $82(11)$ \\
\hline
\end{tabular}

herbivores (see table I). However, when $P$. annua was grown in low density with $A$. thaliana (i.e. in mixed culture), all the plant parts except the reproductive structures had greater biomass when slugs were present (table I). This exception accounts for the scarcity of main effects of slug herbivory, as well as for the interactions between herbivory and culture and density (see figure 2 for an example).

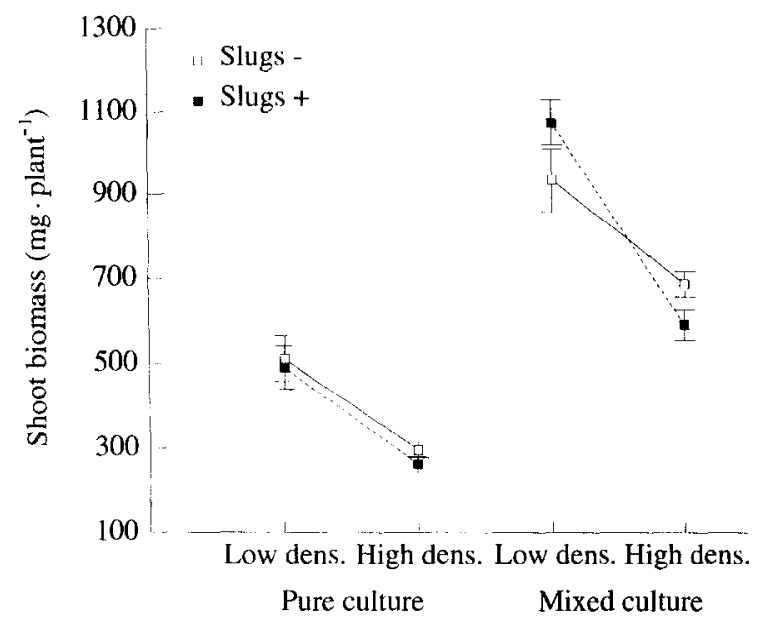

Figure 2. Interactions between culture, density and slug treatments for Poa annua shoot biomass (see table Ila). Qualitatively similar representations can be obtained for total, stem, and leaf biomass (see table I). These have not been included for brevity. Narrow vertical bars show \pm 1 S.E.

\subsection{Biomass allocation}

On average, $P$. annua allocated $12.5 \%( \pm 0.48$ S. E.) of the biomass to roots and $87.5 \%( \pm 0.48 \mathrm{~S}$. E.) to shoots. The average percentages of biomass corresponding to stem and leaf were $44 \%( \pm 0.62 \mathrm{~S}$. E.) and $31.5 \%( \pm 1.26 \mathrm{~S}$. E. $)$, respectively, while only $12 \%( \pm 0.59$ S. E.) was allocated to reproductive structures (see figure 3). The biomass allocation pattern of $P$. аnnua was affected by the main effects of culture and slug herbivory, but not by density (table II). Plants grown in pure stands increased allocation to leaves by $45.7 \%$, and decreased allocation to reproductive structures by $28.1 \%$, compared with the plants grown in mixed stands (see table $I V$ a, figure 3). Biomass allocation to reproductive structures decreased by $8.8 \%$ in plants affected by slug herbivory compared with those with no herbivory (tables $I I \mathrm{~b}$ and $I V$ a). Allocation to other plant parts was not significantly affected by the main effects of herbivory, although herbivory significantly interacted with culture for the percentage of biomass allocated to shoot and to root (table II b), and for the root/shoot ratio (table $I I \mathrm{c})$. These interactions mean that when plants were not subjected to slug herbivory, pure and mixed stands showed similar allocation to shoots and roots, while, when slugs were present, the proportion of biomass corresponding to shoots and roots was different, decreasing by $3.5 \%$ (figure $1 \mathrm{~b}$ ) and increasing by $29.8 \%$ (figure $1 \mathrm{c}$ ), respectively, in mixed compared with pure stands. Therefore, the pure stands showed a lower root/shoot ratio when slugs were present (figure $1 \mathrm{~d}$ ). There were no statistically significant interaction effects of density with the other two factors (table $I I$ ), suggesting that plants responded similarly to herbivory as well as to neighbour identity irrespective of the density (cf. [45]).

\section{DISCUSSION}

\subsection{Culture}

The yield of $P$. annua was strongly affected by the culture treatment, since all the plant parts considered

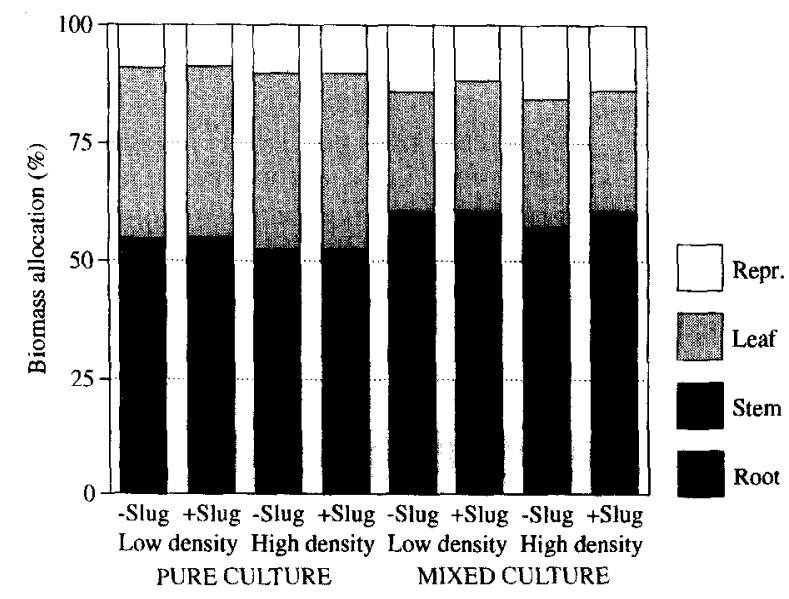

Figure 3. Biomass allocation to various plant parts of Poa annua as affected by culture, density and slug herbivory. 
Table IV. Mean values of (a) proportions of total biomass allocated to vairous plant components, and (b) biomass ratios between various plant components, as they were affected by treatments (see table $I$ ). (i) Culture main effects; (ii) slug herbivory main effects. Standard errors are in parentheses. Conventions in table 1.

\begin{tabular}{lrl}
\hline (a) Biomass $(\%)$ & leaf & repr. \\
\hline (i) Culture & & \\
Pure & $38.6(1.5)$ & $10(0.8)$ \\
Mixed & $26.5(0.6)$ & $13.9(0.6)$ \\
(ii) Slug & \\
- & $12.5(0.8)$ \\
+ & $11.4(0.8)$ \\
\hline
\end{tabular}

(b) Biomass ratios

\begin{tabular}{|c|c|c|c|c|}
\hline (i) Culture & repr./stem & repr./leaf & $\begin{array}{c}\text { repr } / \\
\text { (stem + leaf })\end{array}$ & $\begin{array}{c}\text { repr./ } \\
\text { (stem + leat } \\
+ \text { root })\end{array}$ \\
\hline Pure & $0.23(0.02)$ & $0.28(0.03)$ & $0.12(0.01)$ & $0.11(0.01)$ \\
\hline Mixed & $0.30(0.02)$ & $0.54(0.03)$ & $0.19(0.01)$ & $0.16(0.01)$ \\
\hline (ii) Slug & repr/stem & repr./leaf & $\begin{array}{c}\text { repr./ } \\
\text { (stem + Icaf) }\end{array}$ & $\begin{array}{c}\text { repr } f \\
\text { (stem + leaf } \\
+ \text { root })\end{array}$ \\
\hline - & $0.28(0.02)$ & $0.42(0.04)$ & $0.17(0.01)$ & $0.14(0.01)$ \\
\hline+ & $0.25(0.02)$ & $0.39(0.04)$ & $0.15(0.01)$ & $0.13(0.01)$ \\
\hline
\end{tabular}

in the study had greater biomass in mixed than in pure stands. Nevertheless, the degree of this variation was not uniform in all plant parts, since in mixed stands the proportions of dry matter allocated to reproductive organs and leaves were higher and smaller, respectively, than in pure stands. Differences in competitive ability between $P$. annua and $A$. thaliana may account for these results. In pure stands, high (intraspecific) competition levels experienced by $P$. annua may account for its relatively large diversion of resources toward plant parts directly involved in competition (i.e. potentially leaves and roots). In contrast, in mixed stands, plants of $P$. annua were surrounded by weaker competitors (i.e. plants of $A$. thaliana) which probably enabled their allocation of more resources for the growth of reproductive organs (cf. [43]). The high fertility of the soil and adequate water used in the experiment may account for the absence of differences between pure and mixed stands in the proportion of biomass allocated to roots. In other words, the high fertility of the soil made the effects on allocation of competition for soil resources negligible compared with those caused by the plant-plant interactions occurring above ground (see [58]). This interpretation is based upon the notion $[11,18]$ that plants concentrate their growth in those parts of their anatomy whose function is most constrained by the environment (i.e. leaves in the present case) $[28,52]$.

The central idea of the $r$-and $K$-selection concept $[39,48]$ is that populations experiencing high density-independent control are under positive selection to allocate more resources to reproduction (i.e. an $r$ strategy is relatively favoured) than populations experiencing high density-dependent regulation (i.e. a $K$ strategy is favoured). Accordingly, Gadgil and Solbrig [27] hypothesised that, in situations where plants are closely packed, production of non-reproductive tissues would be favoured, thereby enhancing reproduction at later stages in the life-history. Our results agree with this prediction, as allocation to reproductive organs was lower in pure stands (exhibiting low space availability) than in mixed stands, where the availability of space was greatest due to the relatively small size of A. thatiana.

Law et al. [38] found that $P$. annua seeds originated in continuously disturbed habitats with high availability of bare ground (i.e. mostly experiencing density-independent regulation), produced plants which were generally short lived and with rapid development to reproduction when grown in a standard environment. Conversely, seeds from less disturbed communities, in which the individuals were closely packed with others of their own or different species (i.e. predominantly experiencing density-dependent regulation), produced long lived plants, with longer prereproductive periods. These results indicated that there were genetically-determined differences in most components of the life histories between the two kinds of plant populations (see also [54]). The greater allocation to reproductive organs we observed in mixed stands, suggests a shorter life cycle of $P$. annua than in pure stands. This, in turn, suggests that the patterns of reproduction observed by Law and co-workers could have been caused by the differences in spacing existing between the habitats they studied, and supports the hypothesis [38] that density-dependent regulation has directly contributed to the diversification of the life histories of $P$. апnиa, and to its high genetic variability [22].

\subsection{Density}

Why was allocation pattern affected by culture but not by density? Both treatments had effects upon space availability, although it is likely that such effects differed in some way. Within the culture treatment, differences in space availability resulted from changes in the specific identity of the neighbours surrounding each individual of $P$. annua (i.e. conspecifics in pure stands and plants of $A$. thaliana in mixed stands). This 
meant that $P$. annua interacted with neighbours of different size and shape in each case. Hence, not only space availability, but also the geometry of space differed between pure and mixed stands [24]. Again, if plants tend to concentrate their growth in those parts of their anatomy which are more constrained by the environment (see above), it is likely that such differences led to a different allocation pattern in each kind of culture $[50,55]$. Conversely, changes in space availability within density treatment were due to variations in the number of plants per surface unit, but, as the specific identity of the plants did not change because of the treatment, it seems reasonable that the geometry of the space did not vary in this case as strongly as between pure and mixed stands. This may indeed explain why the biomass allocation pattern of $P$. annua was not affected by density. At high density, the plants experienced greater interference on their growth and, consequently, were smaller than at low density, but this reduction in size was similar in all the plant parts; i.e. it did not alter the plants' allocation pattern since the increase in density stress was uniform throughout the plants' structure.

As discussed before, differences in spacing among habitats seem to have contributed to the diversification of the life histories in $P$. annua. The variation of biomass allocation patterns observed between pure and mixed stands, coupled with the lack of variation within the density treatment, both suggest that changes in neighbour geometry are also relevant for life-history selection. Furthermore, these results also suggest that life-history diversification can be more associated with inter- than with intra-specific competition, since variations in space geometry are more likely to be associated with interspecific interactions.

\subsection{Slug herbivory}

Differential slug herbivory on the two species was intense, with foliage of $A$. thaliana commonly being totally consumed. In $P$. annua, slug herbivory was associated with reductions in the absolute and relative amount of the biomass corresponding to reproductive structures. Similar results have been found by Rai and Tripathi [49], studying the effects of slug herbivory on other annual species, and by other authors studying the effects of artificial defoliation [35, 42] and insect herbivores on plants $[7,32,43,46]$. In addition, Dirzo and Harper [20] found evidences that defoliation by the slug Agriolimax caruanae decreased the reproductive potential of $P$. annua and Capsella bursapastois. Although we have observed evidence of slug attack on $P$. annua, we have never found slugs on the reproductive structures of the plants, nor any sign of direct damage. Hence, the effects of slug herbivory on reproductive biomass were probably indirect, associated with a decrease in the resources devoted to repro- duction in grazed compared with ungrazed stands $[40$, $41,50]$.

Dirzo [19] studied the acceptability of the leaves of $P$. annua and 29 other plant species to Agriolimax caruanae, and Cates and Orians [13] analysed the palatability of the leaves of $A$. thaliana and 99 other species to Ariolimax columbianus and Arion ater. In both studies, the slugs showed high preference for the leaves of annual species, probably because they are frequently soft and thin and rarely contain sccondary compounds. Another feature shared by most of the species preferred by the slugs was that their leaves are positioned close to the ground and therefore are more accessible for the herbivores [19]. A. thaliana exhibits all the characteristics of a highly palatable species - it is an annual species with soft thin leaves, forming a rosette which grows close to the ground - and was among the most preferred species in the study of Cates and Orians [13]. Conversely, the leaves of $P$. annua were less preferred in the study of Dirzo [19], in spite of the fact that this species can sometimes behave as an annual species. In addition, the leaves of $P$. annua grow well above the ground surface, and have silica deposits (phytolits) in them. The latter is a common characteristic among grass species and has been used to explain the rejection that both slugs and snails frequently show for grass leaves $[19,53]$.

A low preference by the slugs for the leaves of $P$. annua, and a high preference for those of $A$. thaliana, may explain the interactions shown by culture and herbivory for root biomass, the percentage of root and shoot biomass, and for the root/shoot ratio. The decrease in the absolute and relative amounts of root biomass (figures $1 \mathrm{a}$ and $\mathrm{c}$ ), and the increase in the percenlage of shoot biomass ( (igure 1 b) shown by the plants in pure stands in presence of herbivory, suggest that the slugs may be feeding below ground (cf. [20]). Similarly, extensive slug feeding on $A$. thaliana may explain why the absolute and relative amounts of $P$. annua root biomass did not decrease in mixed stands in the presence of the herbivores (figures $l$ a and c) (cf. [30]). The data also suggest that slug grazing effects on plant biomass may be modified by interactions between plant density and culture type, as has been previously found by several authors $[9,12$, $17,43]$. The amount of $P$. annua biomass decreased in the presence of herbivory in three situations: in low and high density pure stands, and in high density mixed stands, whereas in the least crowded situations, the low density mixed stands, the opposite occurred; i.e. the amount of biomass was greater in grazed than in ungrazed stands (tables I and II, figure 2). Comparable results have been obtained by Cottam [17] when studying the effects of $D$. reticulatus on Trifolium repens and Dactylis glomerata. This author found that T. repens dominated $D$. glomerata, eventually elimi- 
nating it from ungrazed mixed stands. However, Cottam [17] also found that slug grazing reduced the yield of the most preferred plant T. repens, enabling D. glomerata not only to coexist, but also to grow better and accumulate more nitrogen than grazed conspecifics in monocultures. Our results can be interpreted assuming the preference of the slugs for A. thaliana being modified at high plant density. Accordingly, we suggest two non exclusive possibilities to explain these results. (i) In low density mixed stands, the slugs mainly consumed A. thaliana, resulting in greater availability of space and resources for the growth of $P$. annua, and in turn an increase in the yield of this species. In high density mixed stands, A. thaliana was strongly depressed by its competitive interactions with $P$. annua, which could have resulted in the amount of $A$. thaliana biomass being so low that it is not enough to meet the slug's nutritive requirements. Therefore, $P$. annua plants did not benefit by the differential herbivory on A. thaliana in this case, since they too were attacked by the slugs. (ii) Another possibility is that the crowded environment prevailing in the high density situations may have facilitated the slug attacks on $P$. annua, for example due to the strong overlap which occurred between the leaves of this species and those of A. thaliana at the beginning of the experiment (pers. obs.), and/or due to an increase in the difficulty for the slugs to find A. thaliana in these situations.

An additional explanation to the contrasted effects of slug grazing on plant biomass under different plant densities and cultures is provided by the compensatory continuum hypothesis [40]. In general, this hypothesis states that the harsher the conditions, the more severely plants will be impacted by herbivores, while with more benign conditions plants may be able to equally or overcompensate the effects of herbivory [56]. As discussed before, the least crowded and, therefore, potentially most benign situations in our experiment occurred in the low density mixed stands. According to theory, these would be the places most readily suited for an overcompensatory response to occur. Indeed, the amount of biomass was greater in grazed than in ungrazed low density mixed stands. Whereas, in contrast, in potentially harsher situations (i.e. high density mixed stands and pure stands) the opposite occurred: grazed stands showed less biomass than ungrazed stands. The concordance between theory and observations is not surprising, since $P$. annua appears to be good candidate to show overcompensation. Specifically, it belongs to a family of specics which have cocvolved with grazers and are adapted to being grazed [5]. In addition, this species normally exhibits either annual or biennial life cycles, precisely the kind of life cycles that have been suggested to be the most likely ones to show overcompensation [56]. The mechanisms by which such overcompensatory responses may take place have been reviewed by Whitham et al. [56]. We would like to emphasise the principal conclusion to be drawn from the data, which is that the three factors examined (i.e. culture type, density and slug herbivory) interact in ways that modify the yield and/or biomass allocation pattern of the grass species studied here. These interactions have appeared in relatively uniform experimental conditions for which they are probably the rule rather than the exception in the more complex environment of a natural community.

\section{Acknowledgements}

We thank R. S. Tripathi for collaboration in the development and execution of the experiment, B. A. Hawkins and A. Weis for reviewing earlier versions of the manuscript, and two anonymous referees for numerous suggestions. We also thank R.M. Vidanes for assistance in laboratory sampling. During the preparation of this paper, M. $\Lambda$. Rodriguez has been supported by the Spanish Ministry for Education and Culture (postdoctoral fellowship: FP94 51641052, and CICYT grant: AMB96-116I to A. Gómez-Sal).

\section{REFERENCES}

[1] Archer S., Detling J. K., The effect of defoliation and competition on growth of tillers of two North American mixed-grass prairie graminoids, Oikos 43 (1984) 351-357.

[2] Banyikwa F. F., The growth response of two Last African perennial grasses to defoliation, nitrogen fertiliser and competition, Oikos 51 (1988) 25-30.

[3] Barratt B.I. P., Byers R. A., Bierlein D. L., Conservation tillage crop yields in relation to grey garden slug (Deroceras reticulatum (Müller]) (Mollusca: Agriolimacidac) density during establishment, Crop Prot. 13 (1994) 49-52.

[4] Begon M., Harper J. L., Townsend C. R., Ecology: Individuais, Populations and Communities, 3rd edn. Blackwell, Oxford, 1996, $1068 \mathrm{p}$

[5] Belsky A. J., The effect of grazing: Confounding of ecosystem, community, and organism scales, Am. Nat. 129 (1987) 777 783.

[6] Bentley S., Whittaker J. B., Effects of grazing by a chrysomelid beetle, Gastrophysa viridula, on competition between Rumex obtusifolius and Rumex crispus, J. Ecol. 67 (1979) 79-80.

[7] Bentley S., Whittaker J. B., Malloch A. J. C., Field experiments on the effects of grazing by a chrysomelid beetle (Gastriophysa viridula) on seed production and quality in Rumex obtusifolius and Rumex crispus. J. Ecol. 68 (1980) 671-674.

[8] Bergelson J., Spatial patterning in plants: Opposing effects of herbivory and competition, J. Ecol. 78 (1990) 937-948.

[9] Bonser S. P., Reader R. J., Plant competition and herbivory in relation to vegetation biomass, Ecology 76 (1995) 2176-2183.

[10] Brede A. D., Field apparatus for testing allelopathy of annual bluegrass on crecping bentgrass, Crop Sci. 31 (1991) 13721374.

[11] Brouwer R., Functional equilibrium: sense or nonsense? Neth. J. Agr. Sci. 31 (1983) 335-348 
[12] Burger J. C., Louda S. M., Interaction of diffuse competition and insect herbivory in limiting brittle prickly per cactus, Opuntia fragilis (Cactaceae), Am. J. Bot. 82 (1995) 15581566.

[13] Cates R. G., Orians G. H., Successional status and the palatability of plants to generalized herbivores, Ecology 56 (1975) 410-418.

[14] Clay K., Marks S., Cheplick G. P., Effects of insect herbivory and fungal endophyte infection on competitive interactions among grasses, Ecology 74 (1993) 1767-1777.

[15] Cook R. T., Bailey S. E. R., McCrohan C. R., Slug preferences for winter wheat cultivars and common agricultural weeds, J. Appl. Ecol. 33 (1996) 886-872.

[16] Cooper R. J., Karnok K. J., Herderlong P. R., Street J. R., Response of annual bluegrass to mefluidide under golf course conditions, Appl. Agric. Res. 3 (1988) 220-225.

[17] Cottam D. A., The effects of slug-grazing on Trifolium repens and Dactylis glomerata in monoculture and mixed sward, Oikos 47 (1986) 275-279.

[18] Crawley M. J., Herbivory: the dynamics of animal-plant interactions, University of California Press, Berkeley, 1983, 43\% p.

[19] Dirzo R., Experimental studies on slug-plant interactions I. The acceptability of thirty plant species to the slug Agriolimax caruanae. J. Ecol. 68 (1980) 981-998.

[20] Dirzo R., Harper J. L., Experimental studies on slug-plant interactions II. The effect of grazing by slugs on high density monocultures of Capsella bursa-pastoris and Poa annua, J. Ecol. 68 (1980) 999-1011.

[21] Ellis W. M., The breeding system and variation in populations of $P$. annua L, Evolution 27 (1973) 656-662.

[22] Ellis W. M., Lee B. T. O.. Calder D. M., A biometric analysis of populations of Poa annua L, Evolution 25 (1971) 29-37.

[23] Ester A., Niejenstein J. H., Control of the field slug Deroceras reticulatum (Müller) (Pulmonata: Limacidae) by pesticides applied to winter wheat seed, Crop Prot. 14 (1995) 409-413.

[24] Firbank L. G., Watkinson A. R., On the effects of competition: From monocultures to mixtures. in: Grace J. B., Tilman D. (eds), Perspectives on plant competition, Academic Press, San Diego, 1990, pp. 165-192.

[25] Ford D. J. G.. Cook A., Responses to pulsed light stimuli in a pulmonate slug (Limax pseudoflavus), J. Zool. 214 (1988) 663672.

[26] Frain J. M., Chemoreception and feeding in the grey field slug, Deroceras reticulatum (Müller), with reference to molluscicide formation, Ph. D. thesis, London, 1981.

[27] Gadgil M., Solbrig O. T., The concept of $r$ - and $K$-selection: evidence from wild flowers and some theoretical considerations, Am. Nat. 106 (1972) 14-31.

[28] Gaines M. S., Vogt K. J., Hamrick J. L., Caldwell J., Reproductive strategies and growth patterns in sunflowers (Helianthus), Am. Nat. 108 (1974) 889-894.

[29] Glen D. M., Cuerden R., Butler R. C., Impact of the field slug Deroceras reticulatum on establishment of ryegrass and white clover in mixed swards, Ann. Appl. Biol. 119 (1991) 155162.

[30] Hanley M. E., Fenner M., Edwards P. J., The effect of seedling age on the likelihood of herbivory by the slug Deroceras reticu. latum, Funct. Ecol. 9 (1995) 754-759.

[31] Hanley M. E., Fenner M., Edwards P. J., Mollusc grazing and seedling survivorship of four common grassland plant species:
The role of gap size, species and season, Acta Oecol. 17 (1996) 331-341.

[32] Islam Z., Crawley M. J., Compensation and regrowth in ragwort (Senecio jacobaea) attacked by cinnabar moth (Tyria jacobaeae), J. Ecol. 71 (1983) 829-843.

[33] Johansen T. J., Synnes O. M., The effects of different sowing methods, seed mixtures, and mowing times on the occurrence of annual bluegrass and marsh foxtail in meadows, Norsk Landbruksforsking 6 (1992) 285-296.

[34] Johnston K. A., Pearce R. S., Biochemical and bioassay analysis of resistance of potato (Solanum tuberosum L.) cultivars to attack by the slug Deroceras reticulatum (Müller), Ann. Appl. Biol. 124 (1994) 109-131.

[35] Koptur S., Smith C. L., Lawton J. H., Effects of artificial defoliation on reproductive allocation in the common vetch, Vicia sativa (Fabaceae: Papilionoideae), Am. J. Bot. 83 (1996) 886889.

[36] Law R., The cost of reproduction in annual meadow grass, Am. Nat. 113 (1979) 3-16.

[37] Law R., The dynamics of a colonizing population of Poa annua, Ecology 62 (1981) 1267-1277.

[38] Law R., Bradshaw A. D., Putwain P. D., Life-history variation in Poa annua, Evolution 31 (1977) 233-246.

[39] Macarthur R. H., Wilson E. O., The theory of Island Biogeography, Princeton University press, Princeton, 1967, 203 p.

[40] Maschinski J., Whitham T. G., The continuum plant responses to herbivory: The influence of plant association, nutrient availability and timing, Am. Nat. 134 (1989) 1-19.

[41] Mcnaughton S. J., Compensatory plant growth as a response to herbivory, Oikos 40 (1983) 329-336.

[42] Michaud J. P., Biomass allocation in fireweed Epilobium angustifolium L. (Onagraceae) in response to simulated defoliation, Botanical Gazette 152 (1991) 208-213.

[43] Muller-Scharer H., The impact of root herbivory as a function of plant density and competition: Survival, growth and fecundity of Centaurea maculosa in field plots, J. Appl. Ecol. 28 (1991) 759-776.

[44] Mutikainen P., Walls M., Growth, reproduction and defence in nettles: responses to herbivory modified by competition and fertilization, Oecologia 104 (1995) 487-495.

[45] Mutikainen P., Walls M., Ojala A., Effects of simulated herbivory on tillering and reproduction in an annual ryegrass, Lolium remotum, Oecologia 95 (1993) 54-60.

[46] Myers $J$. H., Interactions between western tent caterpillars and wild rose: a test of some general plant-herbivore hypotheses, J. Anim. Ecol. 50 (1981) 11-25.

[47] Oliveira Silva M. T., Effects of mollusc grazing on the development of grassland species, J. Veg. Sci. 3 (1992) 267 270.

[48] Pianka E. R., On $r$ - and $k$-selection, Am. Nat. 104 (1970) 592597.

[49] Rai J. P. N., Tripathi R. S., Effect of herbivory by the slug, Mariaella dussumieri, and certain insects on growth and competitive success of two sympatric annual weeds, Agr. Ecosyst. Environ. 13 (1985) 125-137.

[50] Schmitd B., Bazzaz F. A., Plasticity in plant size and architecture in rizome- derived vs. seed-derived Solidago and Aster, Ecology 71 (1990) 523-535.

[50] Silvertown J. W., Introduction to plant population ecology, 2nd edn. Longman Scientific \& Technical, Harlow, UK, 1987, $229 \mathrm{p}$. 
[52] Snell T. W., Burch D. G., The effects of density on resource partitioning in Chamaesyce hirta (Euphorbiaceae), Ecology 56 (1975) 742-746.

[53] South A., Terrestrial slugs. Biology, ecology and control, Chapman and Hall, London, 1992, 428 p.

[54] Till-Bottraud I., Wu L., Harding J., Rapid evolution of life history traits in populations of Poa annua L, J. Evol. Biol. 3 (1990) 205-224.

[55] Watkinson A. R., White J., Some life-history consequences of modular construction in plants, Philos. T. Roy. Soc. Lond. B. 313 (1985) $31-51$.

[56] Whitham T. G., Maschinsky J., Larson K. C., Paige K. N., Plant responses to herbivory: The continuum from negative to positive underlying physiological mechanisms, in: Price P. W., Lewinsohn T. M., Fernandes W., Benson, W. W., Plant-animal interactions: Evolutionary ecology in tropical and temperate regions, Wiley, New York, 1990, pp. 227-256.

[57] Whittaker J. B., Invertebrate grazing, competition and plant dynanics, in: Anderson R. M., Turner B. D., Taylor L. R., Population dynamics, Blackwell, Oxford, 1979, pp. 207202.

[58] Wilson S. D., Tilman D., Plant competition and resource availability in response to disturbance and fertilization, Ecology 74 (1993) 599-611.

[59] Young A. G., The effect of microclimate on slug activity in the field, in: Henderson I., Slugs and snails in world agriculture, British Crop Protection Council, Thorton Heath, 1989, pp. 263270.

[60] Zar J. H., Biostatistical analysis, 2nd edn. Prentice-Hall, Englewood Cliffs, 1984, 718p. 